\title{
GRAIN MOLDS IN THE TROPICS: PROBLEMS AND IMPORTANCE
}

\author{
R. J. Williams and D. McDonald
}

International Crops Research Institute for the Semi-Arid Tropics, Patancheru P.O., A. P. 502 324, India

\section{INTRODUCTION}

The tropics, which lie between the latitudes $23.5^{\circ} \mathrm{N}$ and $23.5^{\circ} \mathrm{S}$, are characterized climatologically by uniformly high temperatures throughout the year, and by high relative humidities for varying periods depending on the duration of the summer rainy season (64). Many countries in the tropics have high rates of population growth, high incidence of debilitating human diseases, low per capita income, low availability of foreign exchange, low productivity of food crops, and increasing levels of hunger and malnutrition $(16,21,74)$. One of the greatest challenges facing the world community is how to provide sufficient food of adequate quality to satisfy the minimum nutritional requirements of the ever-increasing human populations in these tropical less-developed countries $(35,44,75)$. During the last two decades considerable attention has been given to the development of improved technology for food crop production in the tropics, and significant gains have been made, particularly with irrigated wheat and rice (11). The primary emphasis has rightly been, and continues to be, on ways to increase grain production per unit area of land. Plant breeding plays a major role in this effort, and in the process of producing cultivars with increased grain-yield potential many plant characters, such as height, tillering capacity, grain numbers per inflorescence, structure and position of grain bearing organs, duration from planting to maturity, crop heterogeneity, and grain quality, are or can be considerably modified. In addition to increasing yield potential, however, these modifications can increase crop vulnerability to adverse environmental factors such as drought, late rains, pests, and pathogens. Phytopathologists in crop improvement programs attempt to minimize the possibility that new improved cultivars will carry high levels of 
susceptibility to economically important plant pathogens. Traditionally, as crop pathologists, their concern has been the pathology of the crop up to the point of harvest, and not the pathology of the grain after harvest. The qualitative and quantitative changes in crops and grain brought about by plant improvement efforts can have considerable effects on the vulnerability of the grain to invasion by fungi, in the field and store, which in the high-temperature and high-humidity tropical environment can result in considerable losses in quantity and quality of seed for farmers and grain for consumers. In this review we attempt to demonstrate the importance of grain molds in the tropics as factors reducing the quantity and quality of seed and food grains and to emphasize the need for increased attention to their control as an essential component of the effort to solve the problems of hunger and malnutrition of a vast segment of mankind.

\section{TERMINOLOGY}

\section{Grain Molds}

For the purpose of this review we have taken the simple definition of grain molds as "fungi that grow on or in seeds." They have traditionally been divided into two basic groups: $(a)$ field fungi, and $(b)$ storage fungi $(9,10)$.

Field fungi invade grain before harvest or before the grain is threshed, and require a moisture content in equilibrium with relative humidities of 90-100 percent.

Storage fungi, as the name indicates, invade grain primarily during storage and require a moisture content in equilibrium with relative humidities of 70-90 percent.

The field fungi, which have previously received little attention in reviews on grain molds and which are of major importance in the tropics, can be divided into three subgroups: (a) specialized pathogens that invade developing or mature grain, and which may or may not cause visible damage; $(b)$ unspecialized highly pathogenic fungi that invade developing grain: and (c) unspecialized, primarily saprophytic fungi that invade moist mature grain. They may survive for years in dry grain, but die rapidly in grains held at moisture contents in equilibrium with relative humidities of 70-75 percent (31).

The storage fungi, mainly several species of Aspergillus and Penicillium, are all primarily saprophytic, but they can be divided into subgroups based on their moisture requirements $(10)$.

One long-standing basic tenet in the literature on grain molds has been that storage fungi do not invade grain to any significant degree in the field even when harvest is delayed by heavy rainfall. There is, however, a considerable body of evidence collected in the past eight years indicating that Aspergillus flavus, the storage mold with the highest minimum moisture requirement for growth, can and does invade grain to a significant degree while it is on the 
mother plants in the field, and that the toxins it produces (aflatoxins) can build up to appreciable levels in grain before harvest $(3,5,12,26,29,65,73,78)$. In the USA this phenomenon appears to be more frequent in, though not confined to, the warmer, wetter regions of the South, and it is likely to be a common and important phenomenon in the tropics.

\section{Grain Weathering}

The term "grain weathering" refers to the adverse effects of the environment on grain while it is on the mother plant in the field. Other terms used to describe this phenomenon include grain deterioration, field deterioration, head blight, head mold, seed mold, and grain mold. The major cause of grain weathering is the invasion of the developing or mature grain by fungi, as indicated by the preponderance of the use of "mold" in descriptive terminology. Related factors that promote or contribute to grain weathering include: prolonged rainfall during grain development and after maturity; alternate wetting and drying; and bird and insect damage.

\section{Grain Spoilage}

The term "grain spoilage" is used to describe the adverse effects of the environment on grain in storage. The primary factors causing grain spoilage are storage fungi, insects, and rodents, with temperature and humidity being the main determinants of the extent of damage by fungi and insects. High temperature per se, resulting from the development within the grain of certain fungi (particularly Aspergillus candidus and A. flavus), causes chemical deterioration of the grain, and if high enough, charring or "bin burn."

\section{Grain-Replacement Diseases}

We have pondered on whether the grain-replacement diseases, e.g. smuts and ergots, should be included in a discussion on grain molds. As most grainreplacement pathogens invade the unfertilized ovaries, either systemically or through the ovary wall or stigmas, and develop in place of the grain, they do not qualify as grain molds. We have, however, included diseases where the grain is only partially replaced, e.g. Karnal bunt of wheat, and those whose causal agents are internally seed-transmitted. Readers who want more information on the grain-replacement diseases are directed to the recent review article on this subject by Luttrell (32).

\section{THE GRAIN MOLDS}

\section{Field Fungi and their Effects}

Developing and mature grain provides a rich substrate for fungi, the former being invaded of necessity by pathogenic fungi, and the latter being vulnerable to invasion by a large number of saprophytic as well as pathogenic fungi. Warm 
wet weather from the time of flowering promotes field molds. In the wettest regions of the tropics, where there may be little or no dry season, rice and maize are the predominant grain crops. In the drier regions, where there is a distinct winter dry season of 5-9 months duration, sorghum and millets, several grain legumes, and groundnut are the major summer grain crops. In the more distal regions of the tropics, in the subtropics, and at high elevations in the tropics, where winters are relatively cool and winter rains may occur, wheat is grown during the appropriate season.

In this section of the review we summarize information on the field molds of the major tropical cereals, oil-seed legumes, and pulses, and the damage that they cause.

MAIZE Maize is a very important food crop throughout the tropics, with about 60 percent of the world's 131 million ha grown in less-developed countries (16). The crop is grown on a large scale in the wet lowland and highland tropics. If maize encounters wet weather from the start of silking, the developing cobs, despite the protective covering provided by the husk, can be invaded by several fungi that cause cob rot, kernel discoloration, loss of viability, vivipary, mycotoxin contamination, and subsequent seedling blights (Table 1).

The occurrence of stalk rots, severe leaf damage, insect and bird damage, and lodging can increase the problems of cob and kernel rots (59). Damage to grain by insects and other agencies increases the incidence of $A$. flavus infection in maize grain in the field (69), as does drought stress (78). High temperatures after infection favor aflatoxin production (63).

The field fungi that invade maize cobs can cause considerable damage, particularly in humid areas, reducing yield and quality, and feed and seed value. In addition, several important leaf and stem pathogens can be seedtransmitted, including Helminthosporium spp., Peronosclerospora spp. (in moist grain for short periods after harvest), Diplodia spp., Gibberella spp. and Fusarium spp. $(59,71)$.

RICE Rice is one of the most important food crops in the tropics, with about 97 percent of the world's 145 million ha grown in less-developed countries (16). The crop is particularly important in the lowland humid tropics, where it frequently encounters warm wet weather during the flowering and grain-filling periods. In the tropics much of the rice does not get threshed immediately after harvest but is piled or stacked for some time in the fields (49).

Lemmas and paleas enclose and adhere tightly to the mature grain. They are not removed during the threshing processes and rice is generally dried, stored, and transported protected by these organs. Despite this protective enclosure, developing and mature grains are vulnerable to invasion by many fungi, 


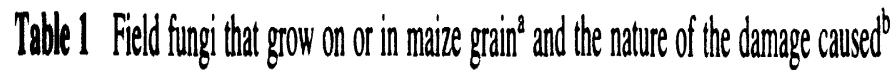

\section{Common name}

Funguss Not diserase of of the dangege caused

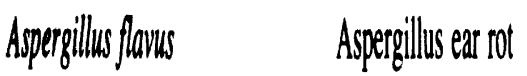

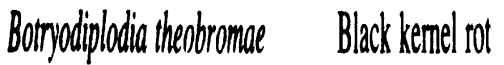

Botrosphheria festicuce

Bomosphperia zace

Claddsporium spp.

Colletorichum graminiciala

Dipbalis sp.

Fusarium spp.

Gibberella ene

Helminthososoriun

maxdis (Rece I)

Nigroporora onsale

Pericillium spp.

Rhinectonia ene

Rhizipous sp.

Ticholdema viride

Usilige maxdis
Physalospora ear of

Grey ear oot

Cladosponium rot

Anthranosese

Diplodis ear oot

Fusariun earkemel fot

Red ear rot

Ear orot

Nigrosporer earclob ot

Pencicllium rot

Rhizoctonis ar rot

Rhizopusear oot

Tricholeme ear ot

Common smut

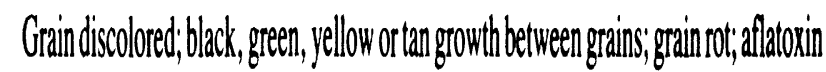
contamination

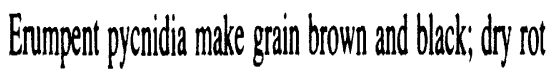

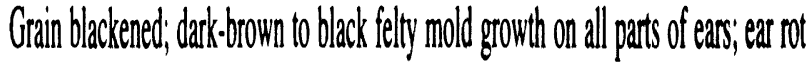

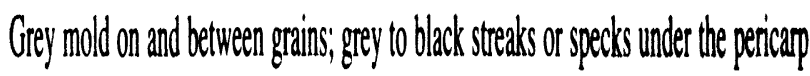

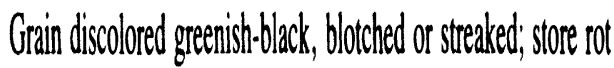

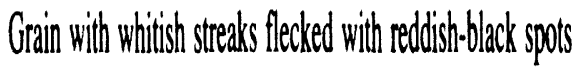

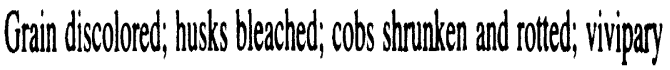

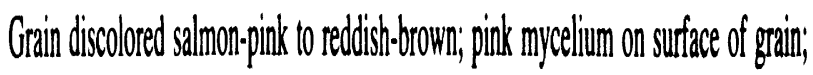
whites strads in percap of late inetede grain

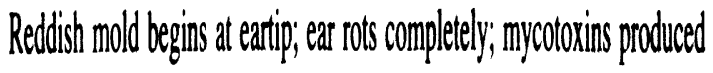

Black felty nod covering gerans, ear ori, seedling blight

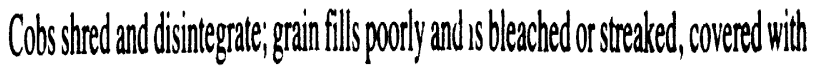
gerey myeclium pepped with masses of found blak spoes

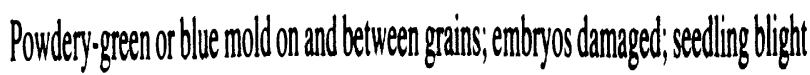

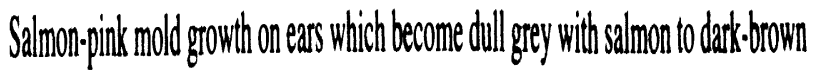

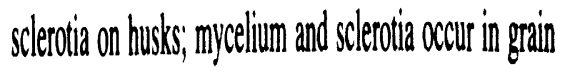

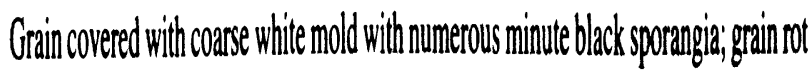
Green fuzzy mold growh on and between grains

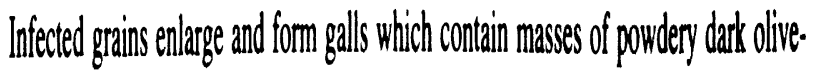
brown to blads spores

Excluding specialized seed-bome pathogens that cause no apparent damage to the grains.

Yajor source: M. C. Shurteff (59). 
resulting in grain discoloration, destruction, or replacement (total or partial), loss of viability, mycotoxin contamination, subsequent seedling mortality, and perpetuation of diseases caused by specialized pathogens. Ou (49) described nine distinct diseases of rice grain, and listed five additional fungi that cause grain discoloration (Table 2). Several of the major fungal pathogens of rice are seed-borne (49), including Pyricularia oryzae (the blast fungus), Helminthosporium oryzae (Cochliobolus miyabeanus) (which causes brown spot), and Gibberella fujikuroi (Fusarium moniliforme) (the causal agent of bakanae).

WHEAT Although wheat is recognized as one of the most important cereals grown in temperate regions, the area sown to this crop in tropical and subtropical countries is enormous, amounting to about 41 percent of the total world wheat area of 237 million ha in 1980 (16).

There are just two named grain "diseases" caused by unspecialized field fungi in wheat (70), although there are several causal species (Table 3). Black point disease has caused considerable damage to wheat in northern India (67) and can be expected when rains are frequent in the post-flowering period. Head blight cannot be regarded as a true grain mold, as the pathogens (several Fusarium spp.) destroy principally the tissues of the inflorescence, but they can also invade the developing grain (70). Infection is promoted by warm wet weather at and after flowering.

Neovossia indica, the causal agent of Karnal bunt, is a specialized pathogen that can transform parts of kernels, or less often complete kernels, into black spore masses. This disease is confined to India, Pakistan, and Mexico.

Other important seed-transmitted specialized pathogens of wheat include Ustilago tritici (which produces loose smut in the subsequent crop), Septoria spp. (causing leaf lesions and glume blotch), and Alternaria triticina (causing leaf blight) (70). Until recently $A$. triticina had been confined to South Asia, the Middle East, and parts of Africa, but in 1981 it was reported for the first time from the Americas (68), causing leaf blight on newly released varieties in the Yaqui Valley area of Mexico.

SORGHUM Sorghum is a major cereal in the drier regions of the tropics (rainy season of $600-1200 \mathrm{~mm}$ in 3-5 months), with about 87 percent of the world's 47 million ha of sorghum cultivated in less-developed countries (16).

Traditional sorghum cultivars in the tropics are generally photoperiodsensitive, flowering just as or after the rains cease, so that their grains fill and mature primarily during dry weather. Improved cultivars have been developed that flower and mature earlier in the season, when soil moisture levels are more favorable for grain filling, which potentially gives higher grain yields. However, the earlier flowering often results in the exposure of developing grain to wet conditions, which promotes the infection of the grain by field fungi. 


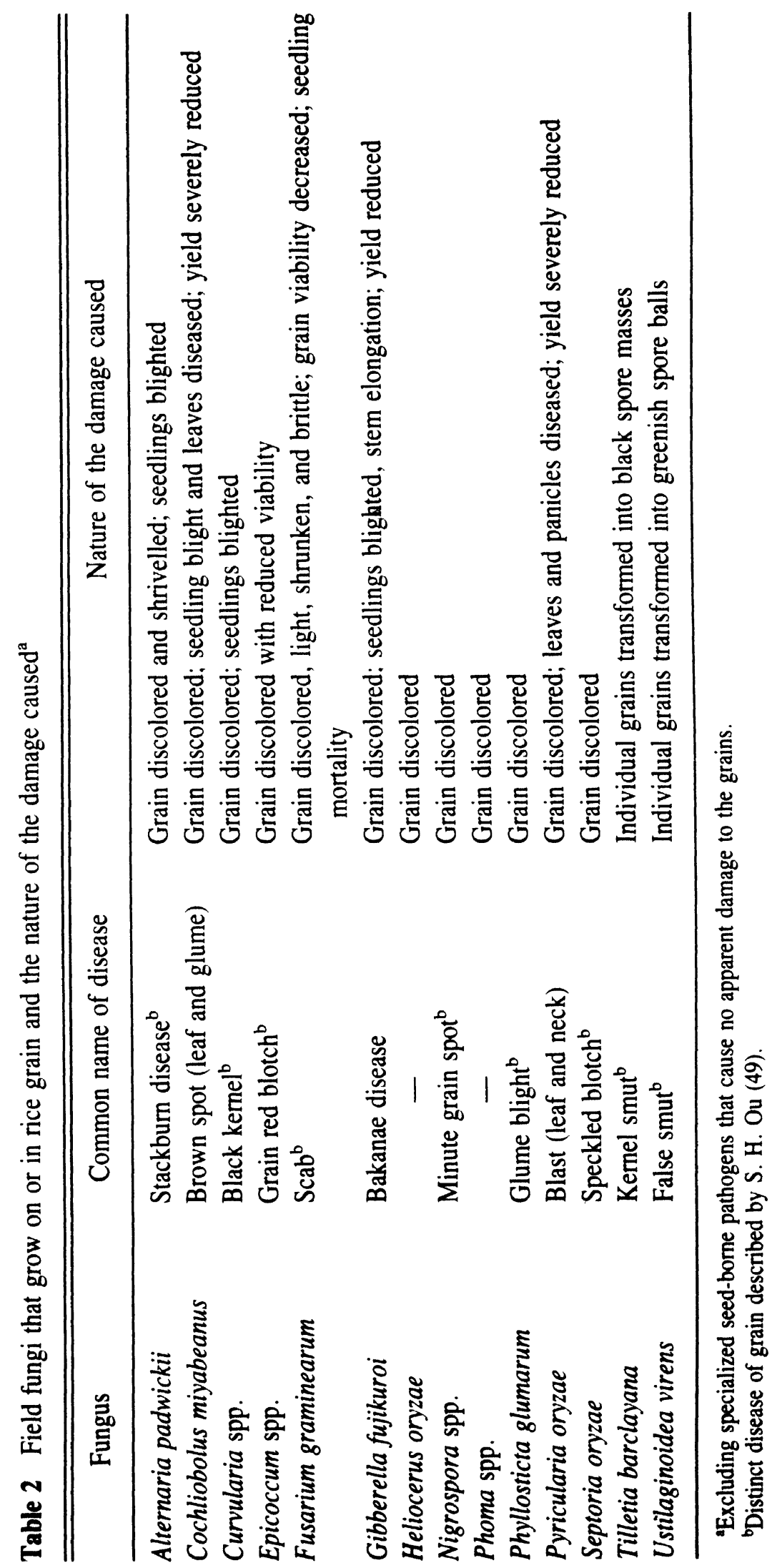




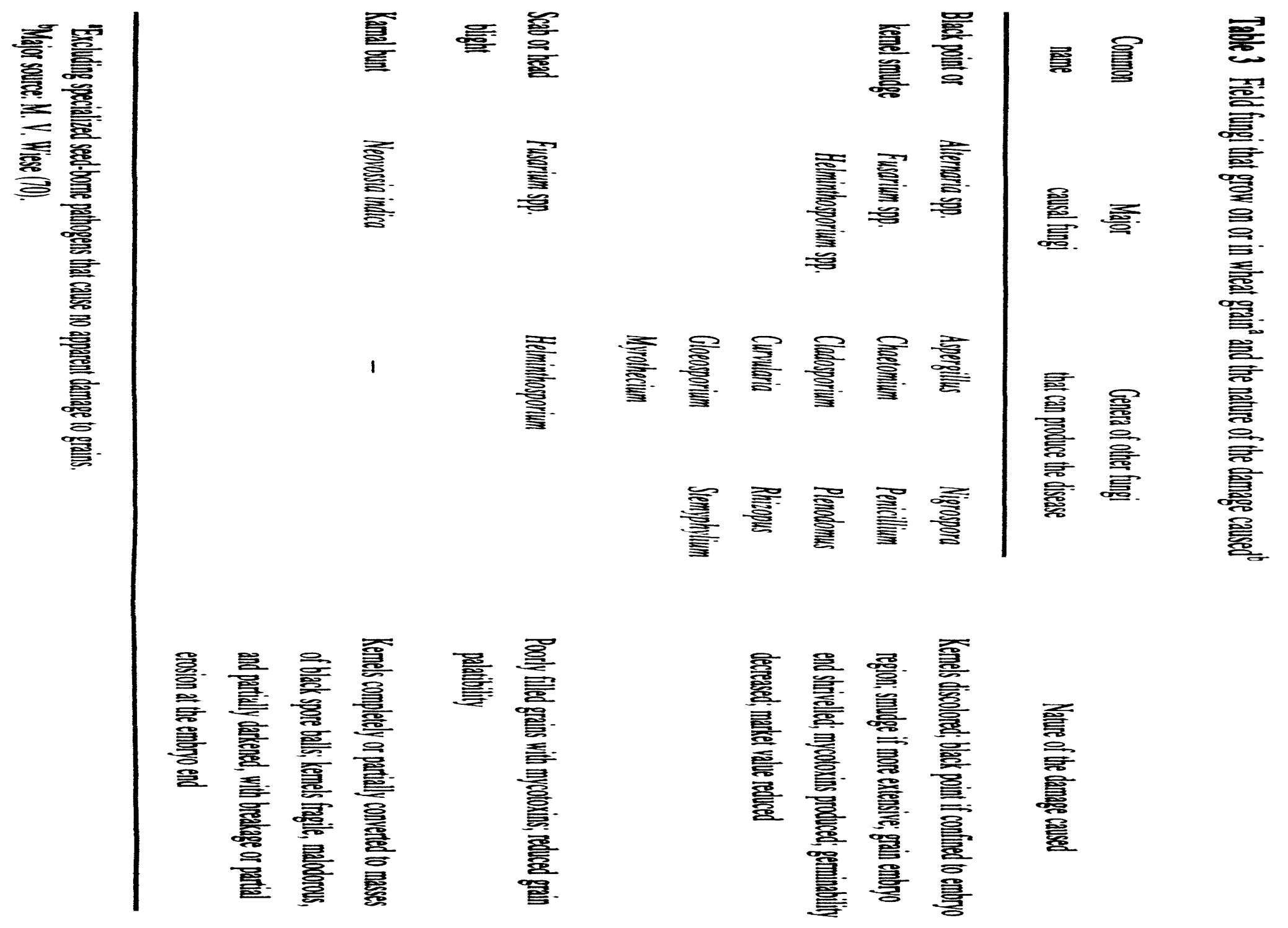


Sorghum grain molds have been recognized internationally in the past decade as major constraints to the successful development and extension of new cultivars with increased capacity for grain yield (22), and as a result the control of sorghum grain molds has become a major part of many sorghum improvement programs (72).

The more pathogenic field fungi that seriously damage grain in sorghum are primarily Fusarium moniliforme and Curvularia lunata $(6,72)$. They invade the young developing kernels, colonizing from the base towards the tip. The primarily saprophytic fungi that invade mature kernels, colonizing from parts of the kernel not covered by the glumes and progressing towards the base, include most frequently Cladosporium spp., Alternaria spp., Phoma spp., and Fusarium semitectum, although fungi in dozens of genera have been isolated from sorghum grain $(6,72)$.

The detrimental effects on yield and quality caused by field grain molds in sorghum, which were recently reviewed in detail (72), include: $(a)$ complete destruction of the grain; (b) severe grain discoloration; $(c)$ reductions in size and weight of grain; $(d)$ reduction in market value; $(e)$ reduction in nutritional value; $(f)$ the production of mycotoxins; $(g)$ vivipary; $(h)$ the loss of seed viability; and (i) subsequent seedling mortality.

There are several specialized pathogens that are seed-transmitted in sorghum, the most important of which include several leaf pathogens (Exserohilum turcicum, Ramulispora sorghi, Gloeocercospora sorghi, Cercospora sorghi, and Colletotrichum graminicola), a stalk rot pathogen (Gibberella fujikur$o i$ ), and sorghum downy mildew (Peronosclerospora sorghi) in moist grain for short periods after harvest $(62,71)$.

PEARL MILLET Pearl millet is grown annually as a staple cereal on about 30 million ha in Africa and South Asia (16). It is the most drought-resistant of the major tropical cereals, and although it can be found from desert oases to high rainfall-derived savanna zones, it is grown as the staple cereal in low rainfall areas (200-500 mm rain in a three-month growing season) in the semi-arid tropics. Consequently, it is not so likely to be exposed to prolonged wet weather after flowering as other tropical cereals, although even in the drier regions of the tropics the problems of unpredictable, unseasonal rains still occur. In West Africa, certain landrace cultivars of pearl millet provide an early cereal component in traditional intercrop systems with later maturing sorghum in wetter areas, and in this situation the crop is more frequently exposed to conditions that promote grain mold.

There are few reports of field grain molds causing significant damage in pearl millet, although many fungi have been isolated from pearl millet grain $(57,58,76)$. The most frequently reported genera are Helminthosporium (Dreschlera, Cochliobolus) and Curvularia, with Helminthosporium rostra- 
tum and Curvularia lunata the predominant species. Ramakrishnan (53) cites one report of Cladosporium herbarum causing moldiness and uneven grain development in pearl millet in southern Africa.

SOYBEAN Soybean originated in East Asia but is now widely grown in both temperate and tropical environments. About 44 percent of the world's 53 million ha of soybeans is grown in less-developed countries (16). The major soybean-producing countries are USA, Brazil, and China. Soybean provides about 40 percent of the world's needs for vegetable oil and is the basis for high protein animal feeds. It has been an important source of dietary protein in East Asia for many centuries but has only recently become important for human consumption in other regions of the world.

The most important fungal pathogens that invade soybean seeds are listed in Table 4 . Seed invasion by these fungi is enhanced by hot, humid weather during pod maturation. An additional 20 species of seed-borne fungi in soybean, of which several can persist in storage for considerable periods, have been listed in a recent review (60).

GROUNDNUT The groundnut or peanut, a native of South America, is now widely cultivated throughout those regions of the world bounded by latitudes $40^{\circ} \mathrm{N}$ and $40^{\circ} \mathrm{S}$, and is of particular importance in the semi-arid tropics. Traditionally an important food legume for the small-scale farmer and urban poor in developing countries, which account for about 70 percent of world production, groundnut now contributes a significant amount of vegetable oil and protein to developed countries, and is regarded as a major oilseed and edible nut crop.

Groundnut is subject to attack by many pathogenic fungi (24a) and several of these (Table 5) are capable of invading and damaging the seed, sometimes with no visible symptoms, i.e. concealed damage. Sowing of such damaged seed can lead to crop emergence failure, and if they enter commerce quality problems will occur. Contamination of groundnut seed with aflatoxins produced by toxigenic strains of fungi of the Aspergillus flavus group is a particularly serious problem in most groundnut-producing countries; this is discussed in more detail below. In addition to the pathogens listed in Table 5, more than 300 species of fungi have been isolated from damaged and from apparently sound seed $(19,20,23-25,36,37,51,61)$. Fusarium spp., Rhizoctonia solani, Macrophomina phaseolina, and several species of Aspergillus, Penicillium, and Pythium have been implicated in pod rots in different parts of the world. The pathogenicity of other fungi is less certain but many species have been found closely associated with damaged seed. The groundnut pod develops to maturity below ground, in close association with the soil mycoflora, and there is evidence of an ecological succession of fungi within the developing pod (34). 


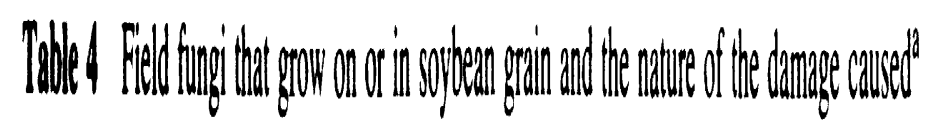

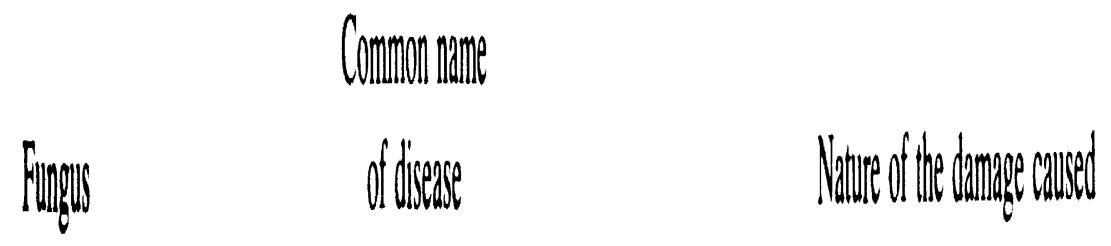

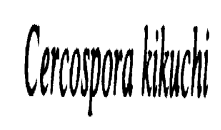

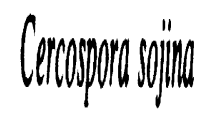

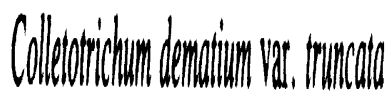

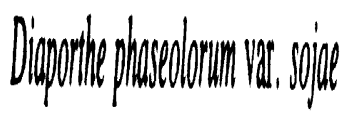

faringm

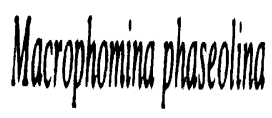

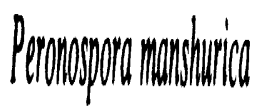

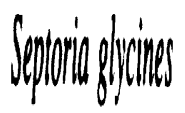

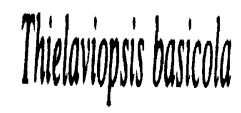

Angkingingin

Fropecele led sont

Anthanamoe

Poc and sem hlingt

Plingwit

Candith

horgllikn

bamingil

lawlot

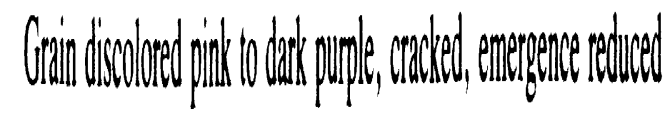

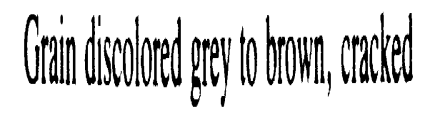

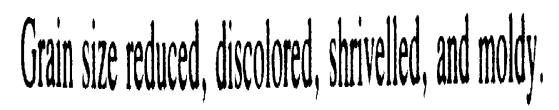

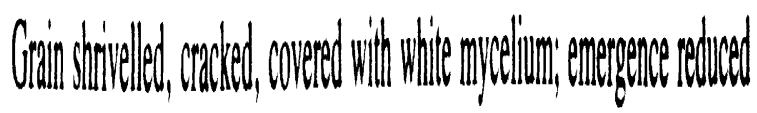

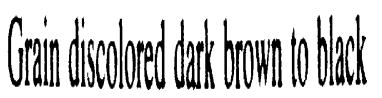

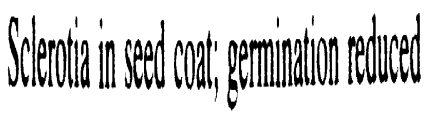

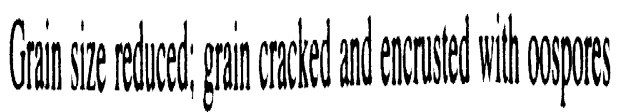

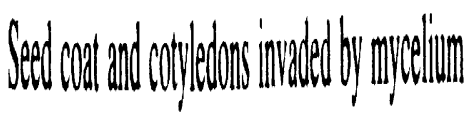

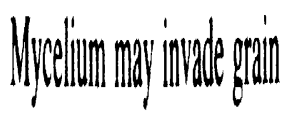

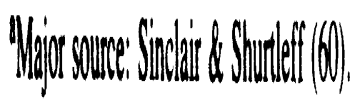


While the shells of sound mature pods are commonly found to contain fungi, the seeds are usually free from infection at the optimum time for harvest. During post-harvest curing and drying there may be appreciable fungal invasion of the seeds if environmental conditions do not favour rapid drying, and a similar invasion occurs if delayed harvesting leads to mature pods drying out slowly in the soil $(36,37)$. In groundnut the division between field and storage fungi is less precise than in the case of cereal crops but there is a general correspondence (34).

PULSES Cowpea, pigeon pea, chickpea, green gram, black gram, and field beans are important pulse crops in the tropics, providing vital sources of protein to the diets of vast numbers of people. About 87 percent of the world's 72 million ha of pulses occurs in less-developed countries, with almost 60 percent produced in Asia (16). Chickpea, pigeonpea, and the grams are of particular significance in the Indian subcontinent, whereas cowpea is more important in Africa. Field beans are less important overall, but do provide substantial sources of vegetable protein in some areas (e.g. highland tropics in Africa and in Latin America).

In tropical less-developed countries the pulse crops are largely grown by small-scale farmers under low-input conditions. They are subject to many pests and diseases and the pods and seeds are particularly susceptible to damage when the crops mature under humid conditions. Some important field fungi that grow in or on seeds of the pulse crops are listed in Table 6, and it is evident that some pathogens infect seed of several different pulses. As the tropical pulses have received relatively little attention from plant pathologists, it is likely that the data given in Table 6 show only a small part of the seed disease picture for this group of crops. Nene et al (43) listed 331 papers in a bibliography of chickpea diseases covering the years 1915-1976, and only 18 referred to seed-borne diseases.

There is little information on the role played by field fungi in storage diseases of pulse grains, but the transmission of several diseases through seed is recorded $(43,45)$. Typical field fungi have been isolated from stored seed and market samples. Emechebe \& McDonald (13) isolated more than 100 species of fungi from stored seed and market samples of cowpea but could isolate only about 20 species from freshly harvested seeds.

The majority of reports on fungi in pulse seeds refer to stored seed. Undoubtedly, the covering provided by the pods and the aerial position of the pods provide considerable protection of pulse grains from fungal invasion by the unspecialized, more saprophytic fungi. Damage to the pods by insects, however, provides entry points for such fungi, and pod-sucking and pod-boring insects are a major problem in pulse production in the tropics. 


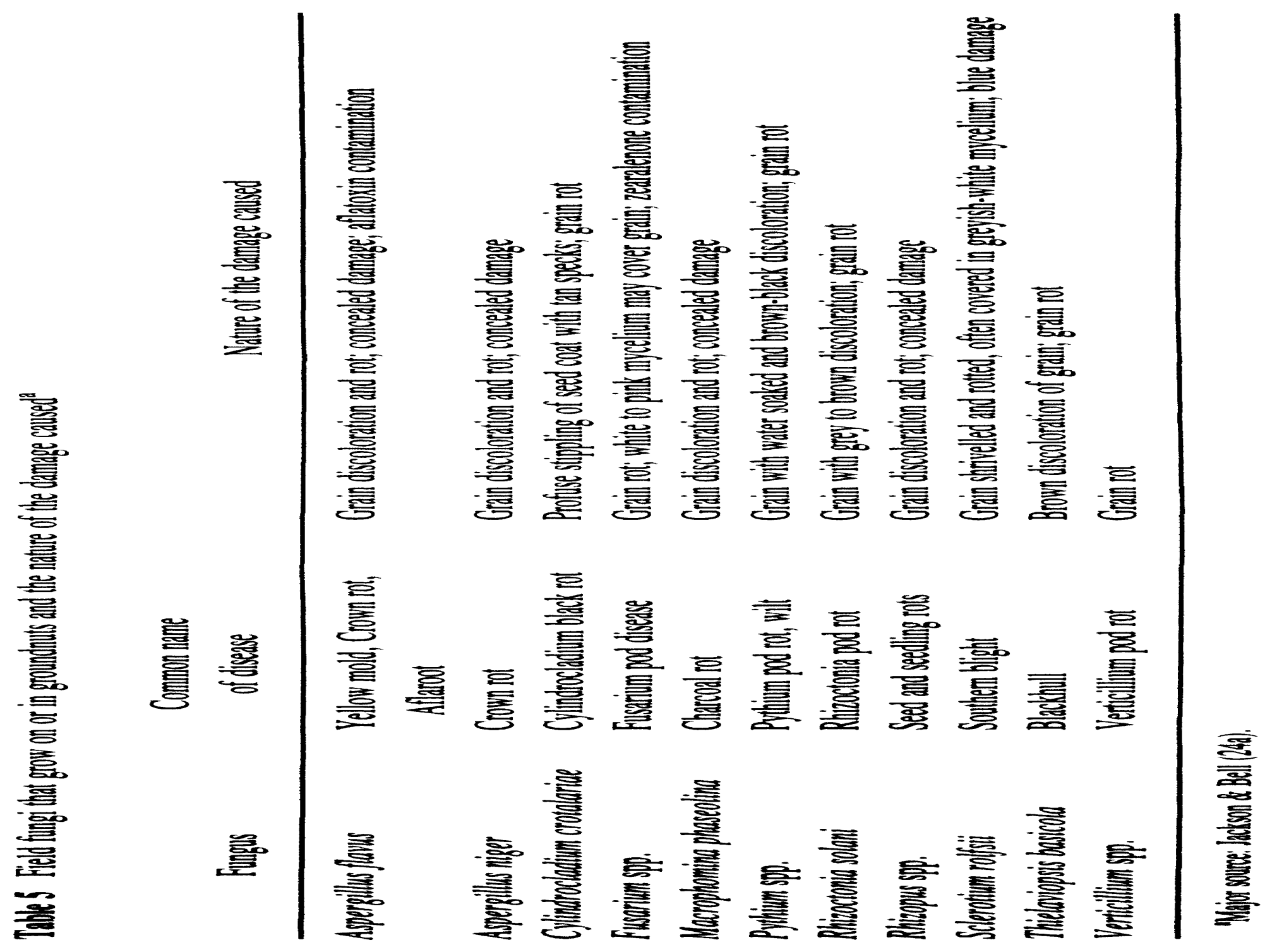




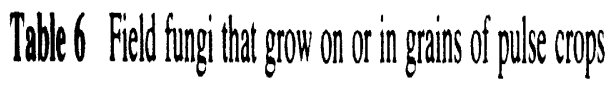

\section{Common name}
Fungus
of diserase
Pulsecrops affected

Allermaria spp.

Ascochtata sp.

Borntis spp.

Cercospon sppe.

Cladosporium spe.

Colledorichum sp.

Connesporas sp.

Dimorthespe.

Elsine phasedi

Funarium spp.

Isariopsis prisedala

Mearophominiap phaserelina

Peronosorors spp.

Phyophthoras spp.

Plesposoringetorín

Pyhium spp.

Rhizicotona scanin

Scleorinina scentionum

Synceptalastrum macemosum

Semonhlium sarcinifome
Leaf spot; floral blight

Ascochty b bligttin, antrananse

Grey mold

Leaf spots and blocthes

Leat and sem blipghts

Antrananose

Taget spots

Semm and pob bight

Sach

Wilts, rot, sem and pod ofos

Angular leat spot

Charcoal Iot

Downy mildedew

Blight

Seed of

Blight

Root, sem and pod tos

Sclentinia oot

Pod rot

Semphylyumblight
Chickerat, pigeonpea

Bean, broad bean, chickpea, piperancea, sainfoin

Bean, broad bean, chickpea, coupea

Bean, clusere bean

Bean, broad bean

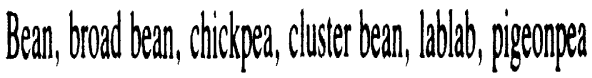

Broad bean, conpea

Bean, conpead

Bean

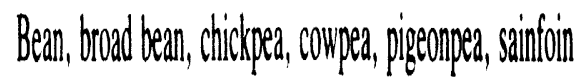

Bean

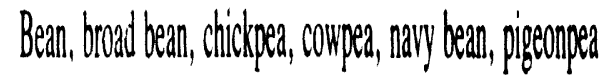

Broad ban

Bean, veluet bean

Chickpea

Bean, chichteat

Bean, broad bean, pireancear

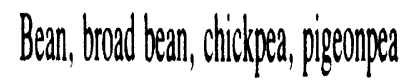

Conpeas

Chickpea 


\section{Storage Fungi and their Effects}

The pioneer and major research worker on molds of stored grain over the past 40 years has been C. M. Christensen of the University of Minnesota, USA. Alone, and together with $\mathrm{H}$. H. Kaufmann, he has published several review articles based on the results of detailed and extensive research studies on storage molds of grain in the USA (7-10). These reviews provide definitive and comprehensive information on storage molds. Thus we do not intend to take up much space repeating what has already been so well presented.

All the major grain storage fungi kill and discolor grain embryos (which are at a higher moisture content than the rest of the grain), causing, for example, "blue-eye" in maize and "sickness" in wheat. This reduces the quality of seed for farmers and grain for consumers. Other detrimental effects of storage molds are grain discoloration, changes in chemical composition, total grain disintegration, the contamination of grain with potent mycotoxins, mustiness and caking, and heating even to the point of combustion.

In a recent review of research on storage molds, Christensen lamented the fact that apart from the work of his research group and their associates, no other major projects have been mounted on storage molds (7). He draws attention to the apparent imbalance between the massive efforts to increase grain production and the paucity of effort to ensure that, once produced, the grain will reach the consumer without significant loss of quantity or quality. Maybe in the temperate regions other researchers have considered that Christensen's work is sufficient research on the subject, and that effort is needed to put into practice the control measures that he and others (e.g. 66) have recommended. In the tropics, however, where climate and resources available to the farmer and grain storers are very different to those in the temperate regions, making safe grain storage even more difficult, considerable research efforts are still needed.

There is a clear recognition of the importance of postharvest food losses in developing countries, which have been conservatively estimated at tens of millions of tons per year (42). In 1975, the VIIth Special Session of the General Assembly of the United Nations passed a resolution committing member States to reduce postharvest food losses by 50 percent by 1985 . There is, however, little precise information available on the magnitude of storage losses of specific crops in specific regions, or on the relative importance of the several causal agents. The collection and assembly of such specific information is urgently needed to define the problem precisely and to develop control strategies.

There is more knowledge about losses in cereal grains and grain legumes than for other food commodities, and the postharvest systems for these grains consist of well defined steps - threshing or shelling, drying, storing, and finally processing. As indicated earlier, the most critical factor affecting the develop- 
storage affecting moisture content, are the main determinants of the extent of losses from storage molds.

In the tropics, the methods available to farmers for drying grain are generally limited to a combination of sun and air drying; thus they are at the mercy of the weather, which is generally highly unpredictable, particularly at the end of the rainy (main growing) season. For example, the 10-year average rainfall at ICRISAT Center in October, the month of sorghum harvest, from 1972 to 1981 was $71 \mathrm{~mm}$, but the range was from $1 \mathrm{~mm}$ in 1978 to $279 \mathrm{~mm}$ in 1974; the November rainfall during the same period varied from 0 to $80 \mathrm{~mm}$ (ICRISAT, unpublished information). So, although traditional crop varieties will have been selected over hundreds of years to fit the general rainfall pattern of the region, there will be years when the maturing or mature grain will be exposed to extended periods of wet weather. In the more humid tropics, where there is no distinct dry season and relative humidities rernain high throughout the year, rice and maize farmers have a very difficult time drying the harvested grain. The availability of cement drying floors is very limited and farmers often utilize the paved highways as a substitute.

Drying can be complicated by the introduction of high-yielding varieties in place of the traditional cultivars, particularly if the new varieties are less photoperiod-sensitive and have a shorter growing cycle. In addition, the increased volume of grain production of new improved varieties and their different grain characteristics may reduce the farmers' abilities to dry and store the grain properly. Considerable work has been done to develop improved grain dryers for the tropics (30), but these will have to match the particular climatic, economic, and social circumstances of particular farmers in order to be truly useful.

Farmers in the tropics have developed local storage systems that generally preclude catastrophic losses from insect pests, storage fungi, and rodents, but nevertheless the losses can be significant, and are accepted as one of the many hazards of life. For example, it is virtually impossible to find any market sample of cowpea in much of West Africa that does not have a high incidence of Bruchid infestation. New high-yield varieties, with different grain characteristics and increased volume of grain, may be much less adapted to the traditional storage techniques, with consequent increased losses. Nevertheless, with small decentralized on-farm storage, the opportunities for large-scale losses are reduced. It is when government agencies procure (or import) large quantities of grain to be stored at centralized facilities that losses can be incurred on a vast scale in the tropics (e.g. about 90,000 tons of imported wheat were declared unfit for human consumption in Food Corporation of India storage facilities in Gujarat, India in August 1982 because of severe fungal spoilage). 


\section{Grain Molds and International Trade}

Despite the problems of hunger and malnutrition of the home populations, some tropical less-developed countries find it economically and/or politically expedient to export food grains, or products derived from them, to more highly developed temperate countries. The export of groundnut and groundnut products has been a major foreign exchange earner for several African and Asian countries over many decades, and more recently wheat, rice, and maize have been exported from the tropics to the temperate regions.

When grains are shipped in bulk internationally from the tropics, there are additional opportunities for molds to develop. The grain may lie exposed to high humidity and rains while on the docks awaiting loading, and condensation problems can be severe in ship holds when the vessels pass from the high temperatures of the tropics to the colder seas and climates of the temperate regions. Thus, grain that was not molded prior to shipment may be considerably molded on arrival at its destination, with consequent risk of harmful effects on consumers or economic loss for the importers and/or the exporters.

\section{THE PROBLEMS OF MYCOTOXINS}

One of the most disturbing and emotive aspects of the invasion of grain by field and storage fungi is the production, by several fungal species, of powerful toxins (mycotoxins) that contaminate food and feed. Prior to the 1960s little work had been done on mycotoxins except in the USSR, and in 1965 it was stated that mycotoxicoses warranted more investigation than they had so far received in the United States (8). Since that time a massive effort has been mounted, primarily in temperate regions, to examine the extent of the problem and to develop control procedures.

In the 1960s much attention was focused on aflatoxins produced by some strains of the Aspergillus flavus group fungi in groundnut and its products. The investigations into turkey "X" disease, the implication of toxic groundnut meal, and the isolation and identification of aflatoxins produced by Aspergillus flavus make interesting reading $(2,4,56)$. Investigations were made to discover at what stage in the development or processing of groundnut the toxigenic fungi invaded the grain, and to see if crops other than groundnut could become contaminated with aflatoxins. The biological effects of aflatoxins on animals and man were studied, and the discovery that in addition to being highly toxic to a wide range of animal species, the aflatoxins were also extremely potent human carcinogens, led to many more investigations being undertaken. Research on other possible mycotoxicoses was also stimulated.

A large number of mycotoxins has now been identified, chemical structures determined, and biological effects studied. There are, however, several sus- 
pected mycotoxicoses whose toxins have not yet been fully identified, and it is likely that several new mycotoxins will be reported in the near future. Natural occurrence of mycotoxins in cereal and legume grains is primarily due to invasion of the grain by toxigenic strains of Aspergillus spp. (which produce aflatoxins, ochratoxin, sterigmatocystin, patulin, and citrinin), Penicillium spp. (ochratoxin, sterigmatocystin, rubratoxins, patulin, citrinin, and cyclochlorotine), and Fusarium spp. (zearalenones, tricothecenes, and ATA-toxin). Several toxigenic fungi have been listed both as field and storage fungi of cereal and legume grains, the most important of these "intermediate" forms being Aspergillus flavus and Fusarium spp.

The literature on mycotoxins is now vast and increasing rapidly. There are several excellent books and review articles on the subject $(40,52,54,55)$, which we recommend to those interested in obtaining more information on mycotoxins and the problems they cause. Of 351 papers on mycotoxins that we reviewed, published in the period 1970-1981, 47 percent were concerned with aflatoxins, 15 percent with zearalenones, and 8 percent with tricothecenes. The latter two groups of mycotoxins are mainly associated with cereal grains and products. In the 1960s the crop that received most attention was groundnut. However, in our survey of the 1970-1981 literature, only 7 percent of papers dealt with mycotoxin problems in this crop, whereas maize and wheat received mention in 22 and 12 percent of papers, respectively, and sorghum, rice, pulses, millet, and soybean were mentioned in 5, 4, 2, 1, and 1 percent of papers respectively. The great majority ( 97 percent) of papers described research done in the temperate regions, with few papers reporting mycotoxin research in the tropics. This imbalance is most disturbing as there is a much greater potential for mycotoxin contamination of grains and foodstuffs in tropical than in temperate environments, particularly for those toxins produced by species of Aspergillus and Penicillium.

While the zearalenone and tricothecene toxins have given cause for concern in temperate regions of America, Europe, and Asia, and the yellow rice toxins in East Asia, the toxin that has received most attention worldwide and is of most importance in the tropics is aflatoxin. We shall use information from groundnut and maize to illustrate important aspects of the aflatoxin problem, as more work has been done on Aspergillus flavus invasion of grain of these crops than for any of the other cereal and legume crops covered in this review.

Aspergillus flavus had long been regarded as a storage fungus and this influenced early research on the aflatoxin problem in groundnut and maize. It was expected that invasion of grain by this toxigenic mold would be found to occur only during postharvest drying or in storage. However, as indicated earlier, it has been clearly established that freshly harvested grains, particularly of groundnut and maize, can have significant amounts of aflatoxin $(3,38)$. Dickens (12), in a summary of factors favouring pre- and postharvest invasion 
of groundnut by toxigenic strains of Aspergillusflavus, listed: (a) damage to the developing pod in the ground during cultivation; $(b)$ damage by pests (insects, mites, millipedes, nematodes, rodents); (c) the effects of pod-rotting fungi; and (d) severe fluctuations in soil moisture. Delayed harvest, with plants becoming senescent and pods drying out slowly in the ground, can also lead to invasion of grain by toxigenic fungi. Maize grain is most susceptible to invasion by Aspergillus flavus during the milk-dough stage (28), and damage to the pericarp is considered necessary in most cases for invasion (78). Insects (borers, earworms, and fall army worms) have been implicated in aflatoxin contamination of maize in the field, by causing damage to grain pericarps and by carrying spores of the fungus into the developing ears (69). In addition, drought stress and "weather damage" are thought to favour fungal invasion and aflatoxin contamination of maize in the field, with high temperatures favouring development of the toxin.

Grain invaded by toxigenic fungi in the field can be the source of serious aflatoxin contamination during crop drying and in storage if environmental conditions favour continued development of the fungi. For both groundnut and maize this situation is more likely to occur in tropical developing countries than in temperate countries where crop drying and storage facilities are generally much more effective. The same is likely to be true for the other cereal and legume crops. Information on human diseases indicates greater aflatoxin problems in the tropics, e.g. Oettle (46-48) suggested that the large differences in hepatoma incidence between males from tropical Africa and those from South Africa and from the drier areas of North Africa could be due to differences in consumption of spoiled grain and moldy foodstuffs. Information from other studies in Africa (50) and in Asia $(1,27)$ supports this indication.

In addition to wet tropical environments favoring molding of grain and foodstuffs, there is evidence that the proportion of toxigenic to nontoxigenic strains of Aspergillus flavus in the soil increases from temperate to tropical regions (33). High temperatures favour aflatoxin production and this is likely to be an additional factor increasing problems from molded grain in the tropics. For some of the Fusarium toxins, however, high temperatures could have the opposite effect upon production (14).

The risk of aflatoxin contamination of a particular crop will be determined by factors of climate, soil, pests and diseases, crop cultivar, crop handling and harvesting methods, drying methods, storage on farms and in the trade, and measures taken to eliminate moldy and low quality grain. Crop cultivars are of considerable importance in terms of their suitability for the environment and cropping systems, their resistance to grain invasion by the toxigenic fungi, and their suitability as a substrate for toxin production $(39,41,77)$.

All the important cereal and legume crops considered have been reported to be contaminated with aflatoxins, but different crops present different aflatoxin 
contamination risks. Some crops such as sorghum may be susceptible to grain invasion by Aspergillus flavus and may provide a good substrate for aflatoxin production, but may have only a small chance of being contaminated because the grain generally matures under dry conditions not conducive to invasion by the toxigenic fungi. Great care should be taken when introducing shorter duration cultivars of such crops or in any way modifying the farming system so that they no longer escape mold attack and mycotoxin contamination. Other crops such as soybean and cowpea are at present regarded as having only a low risk of being contaminated with aflatoxins, for even though their seeds are susceptible to invasion by Aspergillus flavus they appear to be unsuitable substrates for production of aflatoxins. New cultivars of these crops should be checked to ensure that their grain is no more suitable for aflatoxin production than that of the cultivars they are intended to replace.

Prevention of grain contaminaion with aflatoxins and other mycotoxins requires the prevention or control of grain invasion by the field and storage molds that produce the toxins (18). In many cases, however, prevention of grain invasion by molds is not achieved and the grower, consumer, and industry are faced with the problem of dealing with mycotoxin-contaminated grain. Much will depend upon the extent of contamination and the distribution of the mycotoxin within the batch of grain. Fortunately, with most crops there is a good correlation between visible mold damage and mycotoxin contamination, providing the possibility of removal of toxic grains by visual selection. However, occasionally grains may contain appreciable levels of mycotoxins but show little or no external evidence of mold damage (17). Again taking groundnut as an example, growers and purchasers in the USA are alert to the indications of Aspergillus flavus molded grain and have sensitive and reliable aflatoxin testing facilities. They can detect contaminated consignments which can then be diverted to oil extraction and nonfood uses. Slightly contaminated materials may be blended with aflatoxin-free material to obtain an acceptable product, but this is becoming increasingly difficult with progressive lowering of limits of acceptable aflatoxin levels in foods and feeds. The small-scale farmers of the tropics are less well informed and equipped to deal with mycotoxins.

It has been suggested in several countries that the groundnut farmer might be prevented from selling poor quality produce (containing molded and probably toxic grains) to marketing authorities by imposition of quality controls. If the farmer removed molded grains he would then improve the apparent quality of his produce and sell it to the trade, but he would retain a concentrated quantity of moldy and toxic reject grain. Poor and hungry people would be very unwilling to discard or destroy such damaged grain and would be tempted to use it as food for their families and livestock or for local sale. Such a practice wnild radino 
health hazards in the producing areas, including the risk of mycotoxins being present in milk and meat from animals fed on mycotoxin-contaminated products. Practices and problems in the prevention of mycotoxins, with emphasis on less-developed countries, were reviewed in a recent $F A O / U N E P$ publication (15).

To summarize, the factors in the tropics that increase the problems of mycotoxins compared with temperate regions include: $(a)$ higher temperatures and humidities; $(b)$ lower availability of capital for rapid grain drying and correct storage; $(c)$ lower awareness of the problem; $(d)$ less reliable checks on quality of food products; $(e)$ presence of large numbers of poor and hungry people prepared to buy and eat low quality grain; $(f)$ the prevalence of diseases such as hepatitis, gastroenteritis, and malaria that may increase or accelerate the effects of mycotoxins.

A considerable amount of research has been done on the detoxification of grain and several processes have been worked out, particularly for the removal of aflatoxins from groundnut and groundnut products. However, most of the methods have drawbacks and the extraction with solvents and other chemical treatments are generally prohibitively expensive (17). The best answer to the problem of mycotoxin contamination is to prevent the grains or produce from becoming invaded by the toxigenic molds.

\section{CONTROL OF GRAIN MOLDS}

\section{Field Fungi}

The great majority of food-crop farmers in the tropics have small holdings (less than $5 \mathrm{ha}$ ) and very limited monetary resources to apply to the control of any production problem. They have to rely primarily on the inherent qualities of their crop cultivars and their skill in growing them. Thus, it is highly unlikely that the use of pesticides will play any significant role in the control of grain molds before harvest.

There are several cultivar characteristics and cropping practices that can contribute to reducing field grain mold problems. Matching the duration of the cultivar to the "normal" length of the rainy season is important. Traditional cultivars meet this requirement, so that on average they do not develop serious field grain molds. However, because of the erratic commencement and cessation of the rainy season in the tropics even the traditional cultivars will not always fill grain during dry weather. Photoperiod sensitivity, regarded as undesirable by many cereal plant breeders because of its association with tall traditional cultivars of low harvest index, is essential in parts of the tropics with a wide variation in the date of the commencement of the rainy season. It enables the farmers always to plant with the first good rains, taking advantage of the "nitrogen flush" and keeping on top of the weed problem, and yet to know that 
flowering will not occur until a particular time which will generally allow the grain to ripen in dry weather at the end of the rainy season.

Other plant characteristics that can affect the development of grain molds before harvest includes susceptibility to insect damage, physical and chemical characteristics of glumes (husk in the case of maize and pods for legumes), and physical and chemical characteristics of the grain itself. Our experience with the germplasm collections of several cereals and legumes has convinced us of the wealth of variability that exists within crop species, and that new genotypes can be developed that will be able to resist and/or avoid serious grain mold and mycotoxin problems. Care has to be taken, of course, to ensure that the resistance factor(s) do not make the grain unacceptable to consumers. Plant breeders, in their laudable efforts to produce new varieties with increased grain yield potential, must not forget the potential grain mold problems or they will find that despite the promise of more grain the varieties will not be acceptable.

The farmer can reduce post-maturity field grain-mold problems by timely harvest, or in the case of maize by bending the stalks so that the cobs are inverted and thus easily shed rain water, and by rapid drying of the harvested products. The rapid and timely completion of these activities is difficult for the small-scale tropical farmer who does not have the capabilities for mechanized harvesting, threshing, or drying, and who thus has to rely on hand labor (which is expensive at the peak demand periods such as at harvest time) and the weather (which is unpredictable). Thus it is very important that new crop cultivars have built-in mold-avoidance and/or resistance mechanisms.

\section{Storage Fungi}

The basic requirements for avoiding grain molding by storage fungi are maintenance of the grain at low moisture content and/or low temperature, and protection from insect infestation. These are much more difficult to achieve in the tropics than in the temperate regions for many reasons, including differences in climate, resources available, attitudes, and incentives.

On-farm grain storage is very important in developing countries, not only for conserving seed for the next planting, but also for continued feeding of the farmer and his family in the largely subsistence rural environment. Traditional on-farm storage with traditional cultivars of crops such as sorghum and millet in the drier areas of the tropics provides reasonable storage security for the traditional farmers, with low risk of large-scale spoilage (42). On-farm storage of rice and maize in the more humid tropics is more difficult and various projects have been extablished in Asia and Africa to develop improved on-farm drying and storing methods for these crops (42). Government assistance is essential to extend the knowledge of improved technology and to provide incentives and means for their adoption at the farm level. 
The solution of the problems of grain spoilage in large-scale storage in developing countries, which is often a government or quasi-government undertaking, lies primarily in the provision of resources and incentives (economic and status) for the application of known sound storage practices. Readers are directed to "Postharvest food losses in developing countries" (42) for a comprehensive analysis of these problems and recommendations for their solution, and for a list of publications dealing with all aspects of postharvest food losses in the tropics.

\section{PRIORITIES FOR FUTURE RESEARCH}

The first aspect of grain molds in the tropics that needs considerably more research effort, and on which the resources made available for research on other aspects will primarily depend, is the clear definition of the extent and magnitude of losses in quantity and quality of food grains and their effects on human health and welfare. Estimates of losses are available, but more precise data are needed to convince donors and administrators of the need for more resources to be devoted to the control of grain molds. The actual and potential dangers of mycotoxins need to be better evaluated and publicized in the effort to demonstrate the important quality-reducing effects of grain molds in the tropics.

Crop improvement teams, which generally include plant breeders, plant pathologists, and entomologists, should evaluate germplasm collections and new cultivars for the capacity to resist or avoid field fungi, to resist factors such as insect pests that predispose to grain mold development, and to resist storage fungi, and for variability in the capacity to support mycotoxin production when the grain is invaded by toxigenic fungi.

Agronomists need to match crop cultivars and combinations with the seasonal characteristics in particular regions, in order to reduce exposure to environmental conditions conducive for the development of molds.

Agricultural engineers and economists need to work together to develop and evaluate potentially more effective methods of threshing, drying, and storage of grain to reduce the extent of losses from grain molds in storage, on the farm and in large-scale commercial or government facilities.

There is a need for the international donor community to reevaluate the resources devoted to research to increase production relative to research directed to increasing the quantity of produced grain reaching consumers in a fit state for consumption.

Research will enable us to define the problems and provide information on how they can be controlled. The degree of adoption of effective control measures, however, will depend upon the perception of the importance of the problems by producers and consumers, and on the incentives (primarily economic and legislative) provided to reduce them. In many tropical less- 
51. Porter, D. M., Garren, K. H. 1968. An analysis of the endogeocarpic microflora of peanuts in Virginia. Trop. Sci. 10:100-6

52. Purchase, I. F. H. (ed.) 1974. Mycotoxins. Amsterdam: Elsevier. 443 pp.

53. Ramakrishnan, T. S. 1971. Diseases of Millets. New Delhi: Indian Council of Agricultural Research. $152 \mathrm{pp}$.

54. Rodricks, J. V. 1976. Mvcotoxins and Other Fungal Related Food Problems. Advances in Chemistry Series Number 149. Washington DC: Am. Chem. Soc. $410 \mathrm{pp}$.

55. Rodricks, J. V. Hesseltine, C. W., Mehlman, M. A. 1977. Mycotoxins in Human and Animal Health. Illinois: Pathotox. 807 pp.

56. Sargeant, K., Carnaghan, R. B. A., Allcroft, R. 1963. Toxic products in groundnuts: chemistry and origin. Chem. Ind. 41:53-55

57. Sharma, J. R., Basuchaudhary, K. C. 1975. Assessment of seed mycoflora of pearl millet and their control. Indian Phytopathol. 28:388-90

58. Shetty, H. S., Mathur, S. B., Neergaard, P., Safeeulla, K. M. 1982. Drechslera setariae in Indian pearl millet seed, its seed-borne nature, transmission, and significance. Trans. Br. Mycol. Soc. 78:170-73

59. Shurtleff, M. C., ed. 1980. Compendium of Corn Diseases, St. Paul: Am. Phytopathol. Soc. 105 pp. 2nd ed.

60. Sinclair, J. B., Shurtleff, M. C., coeditors. 1975. Compendium of Sovbean Diseases St. Paul: Am. Phytopathol. Soc. $69 \mathrm{pp}$.

61. Subrahmanyam, P., Rao, A. S. 1977. Fungal infection of groundnut pods and aflatoxin accumulation before harvest. Proc. Indian Acad. Sci. 85:432-43

62. Tarr, S. A. J. 1962. Diseases of Sorghum, Sudan Grass and Broom Corn. Kew: Commonw. Mycol. Inst. 380 pp.

63. Thompson, D. L., Lillehoj, E. B., Leonard, K. J., Kwolek, W. F., Zuber, M. S. 1980. Aflatoxin concentration in corn as influenced by kernel development stage and postinoculation temperature in controlled environments. Crop Sci. 20:609-12
64. Trewartha, G. T. 1968. An Introduction to Climate. New York: McGraw-Hill. 408 pp. 4th ed.

65. Tripathi, R. K. 1974. Head fungi of sorghum, phytotoxins and their effects on seed germination. Indian Phytopathol. 27:499-501

66. Tuite, J., Foster, G. H. 1979. Control of storage diseases of grain. Ann. Rev. Phytopathol. 17:343-66

67. Vir, D., Adlakha, K. L., Joshi, L. M., Pathak, K. D. 1968. Preliminary note on the occurrence of black point disease of wheat in India. Indian Phytopathol. 21:234-35

68. Waller, J. M. 1981. The recent spread of some tropical plant diseases. Trop. Pest Manage. 27:360-62

69. Widstrom. N. W. 1979. The role of insects and other plant pests in aflatoxin contamination of corn, cotton, and peanuts-a review. J. Environ. Qual. 8:5-11

70. Wiese, M. V. 1977. Compendium of Wheat Diseases. St. Paul: Am. Phytopathol. Soc. $106 \mathrm{pp}$.

71. Williams, R. J. 1983. Downy mildews of tropical cereals. In Advances in Plant Pathology, ed. D. S. Ingram, P. H. Williams. London: Academic. In press

72. Williams, R. J., Rao, K. N. 1981. A review of sorghum grain moulds. Trop. Pest Manage. 27:200-11

73. Wilson, D. M.. McMillian, W. W., Widstrom, N. W. 1979. Field aflatoxin contamination of corn in South Georgia. J. Am. Oil Chem. Soc. 56:798-99

74. World Bank. 1980. World Development Report, 1980. Washington: World Bank. $166 \mathrm{pp}$.

75. Wortman, S. 1976. Food and agriculture. See Ref. 35, pp. 1-11

76. Yadav, R. K. S. 1978. Perpetuation of Helminthosporium tetramera through bajra seed. Indian Phytopathol. 31: 405

77. Zuber, M. S. 1977. Influence of plant genetics on toxin production in corn. See Ref. 55, pp. 173-79

78. Zuber, M. S., Lillehoj, E. B. 1979. Status of the aflatoxin problem in corn. $J$. Environ. Qual. 8:1-5 